\title{
Export of Recyclable Materials and the Japanese Recycling System: The Case of Used Plastic Bottles*
}

\author{
Masao Satake ${ }^{\dagger} \quad$ Yosiko Yamashige ${ }^{\ddagger} \quad$ Toru Kikuchi $^{\S}$ \\ Tohoku University Seijo University Kobe University
}

\begin{abstract}
In recent years, the increased export of recyclable materials from Japan to Asia, particularly to China, has raised questions regarding Japanese recycling system for containers and packaging, which had assumed no transboundary movement of these materials when first implemented. Facing significant outflow, the Japanese government added the policy to the revised law to encourage local governments to transfer used plastic bottles to designated recyclers who process them for domestic manufactures of final products. However, it is questionable whether such a policy is beneficial as well as sustainable. This study attempts to provide an answer to this question by constructing a simple model of plastic bottle recycling and conducting a positive as well as a normative analysis of the export of recyclable materials in the context of increasing import demand and international market fluctuation.
\end{abstract}

\section{JEL classification: F13; F18}

Keywords: trade of recyclable materials; recycling system; crowding out

\section{Introduction}

Ten years after the enactment of the Basic Law for Promoting the Creation of a Recycling-Oriented Society, Japan continues to pursue the development of a recycling-oriented society to achieve sustainable development.

Received 10 October 2010; received in revised form 7 November 2010; accepted 10 November 2010.

* We are deeply grateful to the referee of this journal for many constructive comments. An earlier version of this paper was presented at the 2009 Annual Meeting of Society for Environmental Economics and Policy Studies and the 2009 Annual Meeting of the Japan Society of International Economics. The authors thank Eiji Hosoda, Atsushi Terazono, Takashi Saito, Keisaku Higashida, and participants at the meetings for their helpful comments. The research of the first author was supported by the Ministry of Education, Science, Sports and Culture, Grants-in-Aid for Scientific Research, 18653021. Two of the authors, Satake and Yamashige, were students of late Professor Kiyoshi Kojima, who had a keen insight into the real world issues, and emphasized the importance of adressing the economic problems associated with them. We sincerely dedicate this paper to our mentor, Prof. Kiyoshi Kojima.

${ }^{\dagger}$ Graduate School of Environmental Studies, Tohoku University, 6-6-20 Aramaki, Aoba-ku, Sendai 980-8579, Japan. E-mail: satake@mail.kankyo.tohoku.ac.jp

$\ddagger$ Department of Economics, Seijo University, 6-1-20 Seijo, Setagaya, Tokyo 157-8511, Japan. E-mail: yamashig@ seijo.ac.jp

$\S$ Graduate School of Economics, Kobe University, 2-1 Rokkodai-cho, Nada-ku, Kobe 657-8501, Japan. E-mail: kikuchi@econ.kobe-u.ac.jp 
However, the recycling system designed by the Japanese government is facing questions in the face of a significant increase in the export of secondary materials such as iron scrap, waste paper, and used plastic to Asian countries, particularly to China, which began in the late 1990s. ${ }^{1}$

In particular, the export of used polyethylene terephthalate (PET) bottles has jeopardized the recycling system for containers and packaging by causing the shortage of and rise in the price of recyclable materials, and accordingly urging the exit of the designated recyclers processing them for domestic manufactures of final products from the market. This "crowding-out effect" of exports on domestic recycling has influenced the current discussion regarding the amendment of the Recycling Law for Containers and Packaging. ${ }^{2)}$

In the 2006 amendment law the government added an article addressing the "smooth delivery of waste plastic bottles for sound recycling" to the basic policy in order to encourage local municipalities to transfer used PET bottles to the designated recyclers and not to the non-designated recyclers, who were considered to process these materials for export. ${ }^{3)}$

The government based its policy change on two key beliefs that it held at the time. First, it argued that dependence on foreign demand was not economically sound because of the negative impact of both short-term fluctuations in the international market and long-term uncertainty in demand for secondary materials among developing countries. ${ }^{4)}$ Second, it argued that the export of recyclable materials through non-designated recycling routes may lead to environmental damage to the trading partners because of improper processing.

In a globalized economy, however, it is questionable whether such a "closed" type of recycling system can be beneficial as well as sustainable. The purpose of our study is to analyze the positive effects of the export of recyclable materials on the recycling system, as well as the welfare effects of a policy change, by constructing a simple model of PET bottle recycling in Japan, in the current context of increasing import demand and international market fluctuation.

Few studies have been conducted in the international trade of recyclable materials since Grace et al.'s (1978) paper was published. While a few researchers such as Duraiappah et al. (2002), Bigsten and Wicks (1996), Haggblade (1990), and Van Beukering (2001) have discussed the crowding-out effects of imports on the domestic recycling market in the importing country, no study to date has analyzed the crowding- or hollowing-out effects of exports on the domestic recycling market in the exporting country. This study makes the first attempt to analyze this issue.

The paper is organized as follows: Section 2 characterizes the PET bottle recycling system in Japan. Section 3 formalizes the municipalities and recycling business sectors into a simple framework. Section 4 presents a model

1) See Kojima (2005).

2) The formal title of law, which was enacted in 1995, is the Law for the Promotion of the Sorted Collection and Recycling of Containers and Packaging.

3) See the 2006 Press Release by the Ministry of the Environment.

4) A recent example of short-term fluctuations is that China suddenly decreased imports of secondary materials during the economic crisis following the Lehman shock in 2008, although the market recovered within a few months. 
of the market equilibrium to describe the conditions that have led the price of used PET bottles to become negative and to analyze the effects of changes in export and domestic prices of recycled products on the prices of used PET bottles. Section 5 discusses some welfare implications of the clause "the smooth delivery of waste plastic bottles" on the policy. Section 6 concludes the study by discussing several implications of the findings.

\section{The PET Bottle Recycling System in Japan}

Japan's PET bottle recycling system aims to recycle and reduce all PET bottles discarded by consumers, which account for $60 \%$ of the total volume of container and packaging waste. Under the recycling system, consumers, municipalities, and businesses are all expected to play relevant roles in reducing waste and promoting recycling.

Figure 1 provides a simple illustration of the PET bottle's "material" recycling system. The solid lines indicate the flow of used PET bottles while the non-solid lines indicate the flow of money. After the municipalities collect containers and packaging waste that has been sorted by consumers, they position the waste within either a designated route or a non-designated route in the recycling process.

Used PET bottles collected by municipalities are first transferred to a designated corporation, which then entrusts the collection and recycling of the used bottles to the designated recyclers. After the designated recyclers use these materials to produce recycled products such as PET plastic flakes and pellets, they sell the recycled products to the manufacturers of final commodities such as fibers and sheets.

Designated recyclers can participate in public tenders of recycling bottles, which are held at designated storage facilities every year. The bidding price of the materials may be positive or negative. When it is positive, the

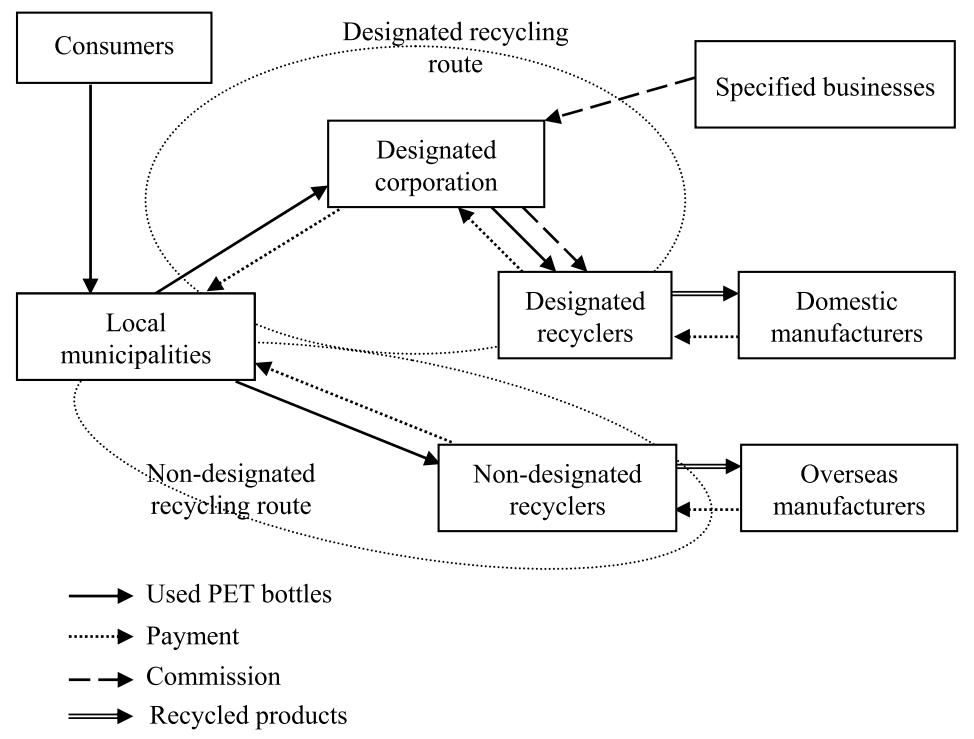

Figure 1 Recycling System for Used PET Bottles 


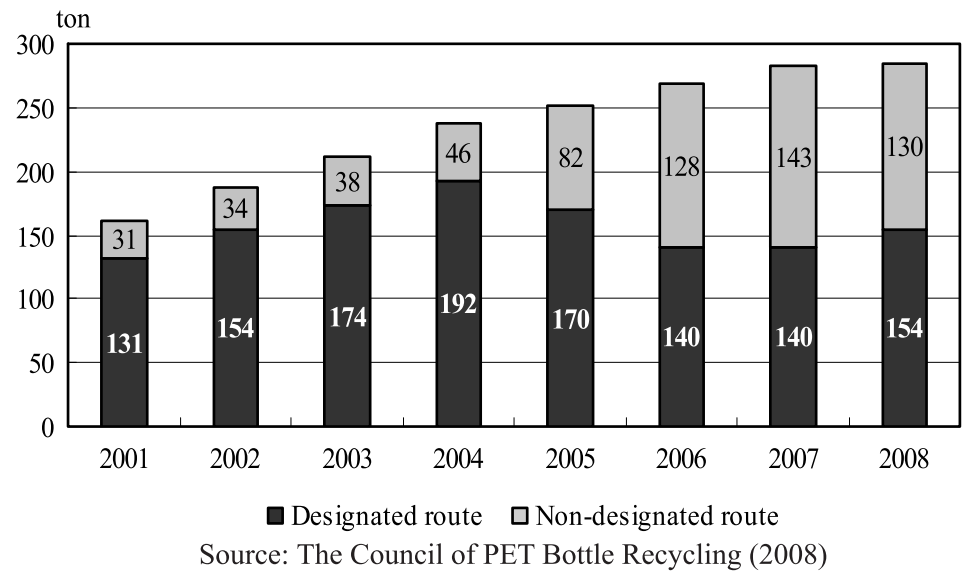

Figure 2 Volume of Used PET Bottles Transferred to Each Recycling Route

designated recyclers pay the designated corporation for the bottles, which then transfer the payment to the municipalities. This transaction is illustrated by the solid and dotted lines between the designated recyclers and the municipalities through the designated corporation in Figure 1.

When the bidding price is negative, designated recyclers receive credits from the designated corporation, which charges a commission to the specified businesses, i.e., PET bottle manufacturers and business entities using PET bottles. ${ }^{5)}$ This process is shown by the broken lines from the specified businesses to the designated recyclers through the designated corporation in Figure 1.

Municipalities, however, do not transfer the entire quantity of used PET bottles collected, to the designated corporation. They directly transfer a portion to non-designated recyclers, most of whom sell the materials overseas. Of the several reasons for a municipal government to transfer these materials to non-designated recyclers, the most important is to earn revenue. The amount transferred to non-designated recyclers, which was meager in the early period of the recycling system, increased gradually until it exceeded the amount transferred to the designated corporation, as shown in Figure 2. Many have raised concerns that this increase would have devastating effects on the Japanese domestic recycling system. ${ }^{6}$

The bidding price of used PET bottles along the designated route had been lower than that along the nondesignated route for every year except for the two most recent years, as indicated in Figure 3. Although gradually increasing, the price along the designated route remained negative between 1997 and 2005. A primary feature of these price movements is that the non-designated price has moved almost parallel to the export price of recycled products, whereas the designated price has moved almost parallel to the domestic price of recycled products.

5) Note that the designated corporation, not the municipalities, pays for the negative bidding price of used PET bottles.

6) A certain quantity of PET bottles used by venders and retail stores is collected not by the municipalities but by the retailers themselves along the so-called "self-collection route." The remaining used PET bottles, collected by neither the municipalities nor the retailers, are either exported or discarded. 


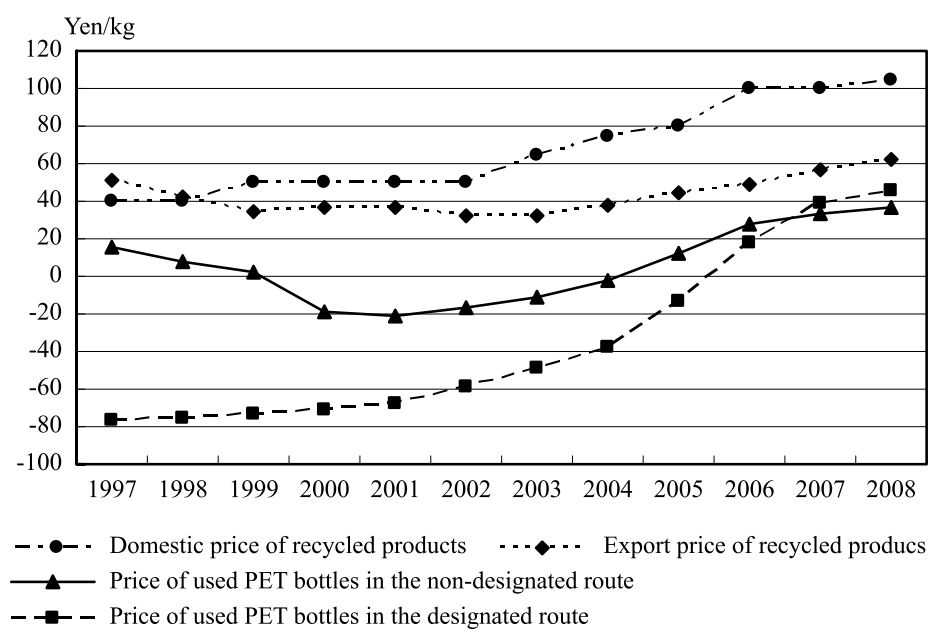

Sources:The domestic price of recycled products is quoted from the price of PET bottle flake shown in Kurita(2009), Table 6-3 of p.138. The export price is calculated from the trade statistics of Ministry of Finance. The price in the designated recycling route is quoted from the Council of PET Bottle Recycling(2008). The price in the non-designated recycling route is the average of prices obtained from the questionnaire survey conducted by Kurita(2009).

Notes: Export price up to 2005 is obtained from dividing the total value of other plastics (H.S code; 3915.90) by the volume of their exports in the category of waste, parings and scrap, of plastics (H.S code;3915). Export price after 2006 is derived from the data of PET (polyethylene terephthalate) scraps of other plastics. (H.S code;3915.90.100).

Figure 3 Export and Domestic Prices of Recycled Products and Prices of Used PET Bottles

\section{PET Bottle Recycling Model}

This section considers the behaviors of local municipalities as suppliers and those of recycling businesses as users of used PET bottles. Every fiscal year, municipalities submit their plans for the volume of sorted used bottles that they will collect, to the central government. It is assumed that the amount of bottles collected by each municipality is fixed at $\bar{X}$ and that the municipalities collect and store the used bottles at a cost of $C_{g}$.

The municipalities transfer the collected bottles either to the designated recyclers, whose products are recycled domestically, or to the non-designated recyclers, whose products are entirely exported. It is assumed that there are numerous municipalities and recyclers who accept the prices of used PET bottles as given. The prices of the used bottles are determined endogenously, while the domestic and export prices of the recycled products such as plastic flakes or pellets, are determined exogenously. 


\subsection{Local municipalities}

Municipalities earn revenue when the PET bottles are priced at a bidding price of $P_{a}$ along the designated route as well as a competitive price of $P_{b}$ along the non-designated route. Assuming that $X_{a}$ and $X_{b}$ represent the quantity of PET bottles delivered to the designated and non-designated recyclers, the revenues that municipalities earn along each route are $P_{a} X_{a}$ and $P_{b} X_{b}$, respectively.

Although they can earn revenue by pursuing the non-designated recycling route, municipalities also face the risk of being unable to sell all their collected materials, as most used PET bottles that are transferred to the nondesignated route are exported to foreign markets. Moreover, prices and transactions along the non-designated route are susceptible to international market fluctuations. When the demand for used PET bottles declines in reaction to fluctuations in the international market of recycled products, non-designated recyclers reduce their purchases of used PET bottles, leading to the possibility that non-designated recyclers may not accept recyclable materials from municipalities that wish to transfer them. ${ }^{7)}$ On the other hand, as the contracts that municipalities have with the designated corporation are long term in nature, municipalities do not face the risk of recyclable materials not being accepted along the designated route, as they are confident that the designated corporation will accept them.

Assuming that the expected sales rate is $\alpha$, when $X_{b}$ units of PET bottles are delivered along the non-designated route, only $\alpha X_{b}$ units can be sold. As $\alpha$ depends on the demand for recycled products by the international market, it is assumed that the given the external condition $\alpha$ is dependent on the amount of $X_{b}$ as expressed in equation (1):

$$
\alpha=\alpha\left(X_{b}\right), \alpha^{\prime}<0, \alpha^{\prime \prime}<0, \alpha(0)=1,0 \leq \alpha \leq 1
$$

Equation (1) implies that as $X_{b}$ increases, the probability of recyclable materials being accepted by nondesignated recyclers decreases, and the expected revenue from the non-designated recycling route becomes $\alpha P_{b} X_{b}$.

If both $P_{a}$ and $P_{b}$ are positive, a local municipality's net revenue $B$ can be expressed as follows:

$$
B=P_{a} X_{a}+\alpha\left(X_{b}\right) P_{b} X_{b}-C_{g}(\bar{X})
$$

As municipalities allocate the total amount of recyclable materials $\bar{X}$ between designated and non-designated recyclers, the total volume of recyclable materials is the sum of the volumes delivered to designated and nondesignated recyclers: ${ }^{8)}$

7) Used PET bottles unsold to non-designated recyclers are stored by the municipalities. Here, it is assumed that there is no storage cost.

8) Municipalities make allocation decisions regarding used PET bottles based on expected revenues rather than actual revenues because they must make their decisions before international market conditions are known. At the beginning of the period, municipalities decide on the volume of used PET bottles to be transferred to the designated corporation and nondesignated recyclers, simultaneously. Recycling business firms then make output decisions based on realized international market conditions. 


$$
\bar{X}=X_{a}+X_{b}
$$

Given that prices $P_{a}$ and $P_{b}$ are exogenous, the optimal behavior of the local municipalities (i.e., the determination of $X_{b}$ ) is characterized by the following condition:

$$
P_{a}=\alpha^{\prime}\left(X_{b}\right) P_{b} X_{b}+\alpha\left(X_{b}\right) P_{b}=P_{b}\left(\alpha^{\prime} X_{b}+\alpha\right)
$$

In Figure 4, the horizontal axis measures the amount of $X_{b}$, while the vertical axis measures $P_{a}$. When $P_{b}$ is positive, the RHS of equation (4) can be depicted as a downward-sloping curve. Given that $P_{b}=P_{b}^{0}$ holds, the RHS of equation (4) becomes $P_{b}^{0}\left(\alpha^{\prime} X_{b}+\alpha\right)$, and $P_{b}^{0}$ at $X_{b}=0$. Accordingly, an increase (decrease) in $P_{b}$ moves the curve upward (downward). The curves intercept the horizontal axis at $-\alpha / \alpha^{\prime}$, indicated by $X_{b}^{\alpha}$. When $P_{b}=P_{b}^{0}$ and $P_{a}=P_{a}^{*}$, the local municipality allocates the quantity $O X_{b}^{*}$ to the non-designated recycling route and the remainder $\left(X_{b}^{*} \bar{X}\right)$ to the designated recycling route. The * notations indicate the equilibrium values.

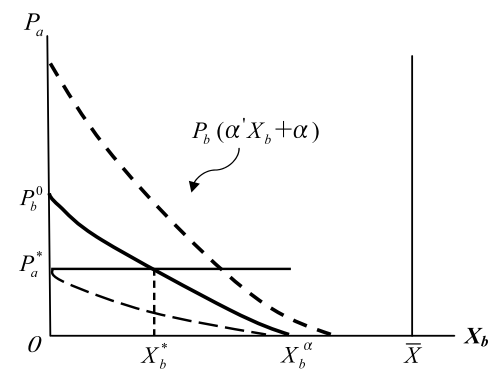

Figure 4 Determination of the Collected Volume in the Non-Designated Recycling/ Designated Recycling

When no revenue is received from the designated route - that is, when $P_{a} \leq 0$ - equation (2) can be modified as follows:

$$
B=\alpha\left(X_{b}\right) P_{b} X_{b}-C_{g}(\bar{X})
$$

In this case, local municipalities sell the quantity $O X_{b}^{\alpha}$ of the recyclable materials to non-designated recyclers and deliver the remainder $\left(X_{b}^{\alpha} \bar{X}\right)$ to the designated corporation for any positive $P_{b}$. On the other hand, when $P_{b} \leq 0$, local municipalities transfer all recyclable waste to the designated corporation because they do not have to pay for the delivery of used bottles along the designated route, whereas they must pay for delivery along the non-designated route. ${ }^{9)}$

Using Figure 4, the local municipality's supply curve can be derived. Given the level of $P_{b}$, an increase in $P_{a}$

9) This model assumes that $P_{b}$ does not fall below zero and that there are no transactions along the non-designated route. In reality, however, there was a period when $P_{b}$ remained negative and several transactions occurred between local municipalities and non-designated recyclers, as shown in Figures 2 and 3. This occurred because the business of nondesignated recyclers has been affected by factors other than the ability to earn revenue such as the flexibility of trade, the formation of continuous relationships, and the support of local recyclers. See Kurita (2009), p.112. 
induces an increase in the supply of recyclable materials to the designated recyclers. At $P_{a}=P_{b}^{0}$, the supply to the designated route reaches its maximum at $O \bar{X}$. On the other hand, when $P_{a} \leq 0$, the supply reaches the minimum level $X_{b}^{\alpha} \bar{X}$. The supply curve for the designated route is thus depicted by $X_{a}^{S}\left(P_{a}\right)$ in Figures 6 and 7, which appear in Section 4.

The supply curve for the non-designated recycling route can be obtained as follows. If $P_{b}>P_{a}^{*}$, then an increase in $P_{b}$ leads to an increase in the supply of recyclable materials along the non-designated route. On the other hand, if $P_{b} \leq P_{a}^{*}$, the supply of recyclable materials along the non-designated route becomes zero, as the local municipalities would allocate all of $\bar{X}$ to the designated recyclers. Their behaviors are summarized by the curve $X_{b}^{S}\left(P_{b}\right)$ in Figures 6 and 7.

\subsection{Recycling businesses}

\subsubsection{Designated recyclers}

Designated recyclers obtain the used PET bottles by competitive bidding and utilize them to produce recycled products for sale to domestic manufacturers. Their profit is obtained by subtracting the cost of obtaining and processing these bottles from the revenue that they earn from selling the recycled products. When the bidding price $P_{a}$ is positive, the bidding price of the recyclable materials multiplied by the quantity of the recyclable waste $P_{a} X_{a}$ is the cost of obtaining the used PET bottles. On the other hand, when $P_{a} \leq 0, P_{a} X_{a}$ represents the revenue designated recyclers receive as a recycling fee from the designated corporation. Therefore, the profits $\Pi_{a}$ can be expressed as follows:

$$
\Pi_{a}=P_{y} Y_{a}-P_{a} X_{a}-C_{a}\left(Y_{a}\right)
$$

where $P_{y}$ represents the price of the recycled products in the domestic market, $Y_{a}$ the quantity of the recycled products, and $C_{a}$ the cost function. According to both the production and cost functions, the following conditions can be imposed:

$$
\begin{gathered}
Y_{a}=F\left(X_{a}\right), F^{\prime}>0, F^{\prime \prime}<0, \bar{Y}_{a}=F(\bar{X}), \\
C_{a}^{\prime}>0, C_{a}^{\prime \prime}>0, C(0)=0 .
\end{gathered}
$$

The first-order condition becomes as follows:

$$
F^{\prime}\left(X_{a}\right)=\frac{P_{a}}{P_{y}-C_{a}^{\prime}}
$$

Equation (8) can be rewritten as follows:

$$
C_{a}^{\prime}=P_{y}-\frac{P_{a}}{F^{\prime}\left(X_{a}\right)} .
$$

Figure 5 depicts the relationships expressed by the above equations. Let the domestic price of recycled products be $P_{y}^{\$}$. Then the production of recycled products occurs between 0 and $Y_{a}^{\$}$, where $Y_{a}^{\$}$ is the output with $P_{y}^{\$}=$ 
$C_{a}^{\prime}\left(Y_{a}\right)$ if $P_{a}>0$. On the other hand, if $P_{a} \leq 0$, the recyclers can produce an output beyond $Y_{a}^{\$}$ because they will receive a recycling fee to cover their deficits. Thus, the optimal output is $Y_{a}^{0}$ if $P_{a}=P_{a}^{0}>0$, but $Y_{a}^{1}$ if $P_{a}=P_{a}{ }^{1} \leq 0$. Depending on the level of $Y_{a}$, the demand for $X_{a}$ can be obtained by equation (7).

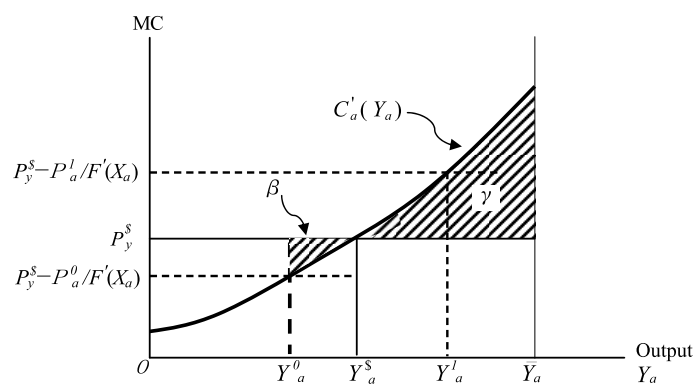

Figure 5 Optimal Output of Recycled Products Produced by the Designated Recycler

As $P_{a}$ decreases, the output $Y_{a}$ and the derived demand for $X_{a}$ becomes larger. On the other hand, as an increase in $P_{a}$ leads to a decrease in profits, it leads to a decrease in demand for $X_{a}$. In summary, the demand for used PET bottles by the designated recyclers can be depicted as the decreasing curve $X_{a}^{D}\left(P_{a}\right)$ in Figures 6 and 7, as an increase in the price of the recycled products $P_{y}$ would shift $X_{a}^{D}$ to the right.

\subsubsection{Non-designated recyclers}

Non-designated recyclers purchase the used PET bottles at price $P_{b}$ for the production of recycled products that they export at the fixed export price $\bar{P}_{e}$. Assuming that $Y_{b}$ represents their total output and $C_{b}$ the costs of other inputs, their profits are calculated as follows:

$$
\Pi_{b}=\bar{P}_{e} Y_{b}-P_{b} X_{b}-C_{b}\left(Y_{b}\right)
$$

The following conditions are further imposed on the production function $G$ and the cost function $C_{b}$ :

$$
\begin{gathered}
Y_{b}=G\left(X_{b}\right), \quad G^{\prime}>0, \quad G^{\prime \prime}<0, \\
C_{b}^{\prime}>0, \quad C_{b}^{\prime \prime}>0, \quad C_{b}(0)=0 .
\end{gathered}
$$

The first-order condition can be obtained as follows:

$$
\bar{P}_{e} G^{\prime}\left(X_{b}\right)=P_{b}+C_{b}^{\prime}\left(Y_{b}\right)
$$

As shown in the usual negative slope demand curve $X_{b}^{D}\left(P_{b}\right)$ in Figures 6 and 7, an increase in the export price shifts the demand curve upward. 


\section{Equilibrium Analysis}

\subsection{Market equilibrium}

Figures 6 and 7 depict the combined demand and supply curves. Quadrants I and IV depict the demand curve $X_{a}^{D}$ and the supply curve $X_{a}^{S}$ for the designated recycling route, whereas quadrant II depicts the demand and supply curves $X_{b}^{D}, X_{b}^{S}$ for the non-designated route. Figure 6 illustrates a case in which $P_{a}>0$ and $P_{b}>0$ and Figure 7 illustrates a case in which $P_{a} \leq 0$ and $P_{b}>0$, assuming that the equilibrium prices are $P_{a}^{*}$ and $P_{b}^{*}$, respectively, and the equilibrium quantities of PET bottles recycled along the designated route and the non-designated route are $X_{a}^{*}$ and $X_{b}^{*}$ respectively.

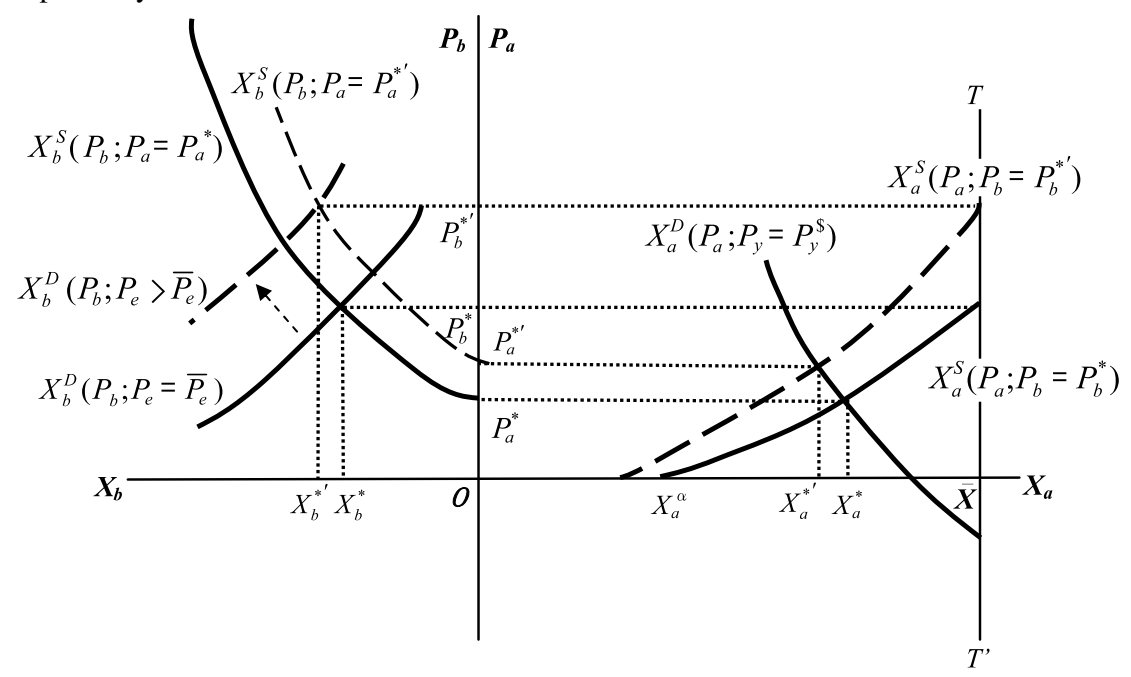

Figure 6 Market Equilibrium with $P_{a}>0$

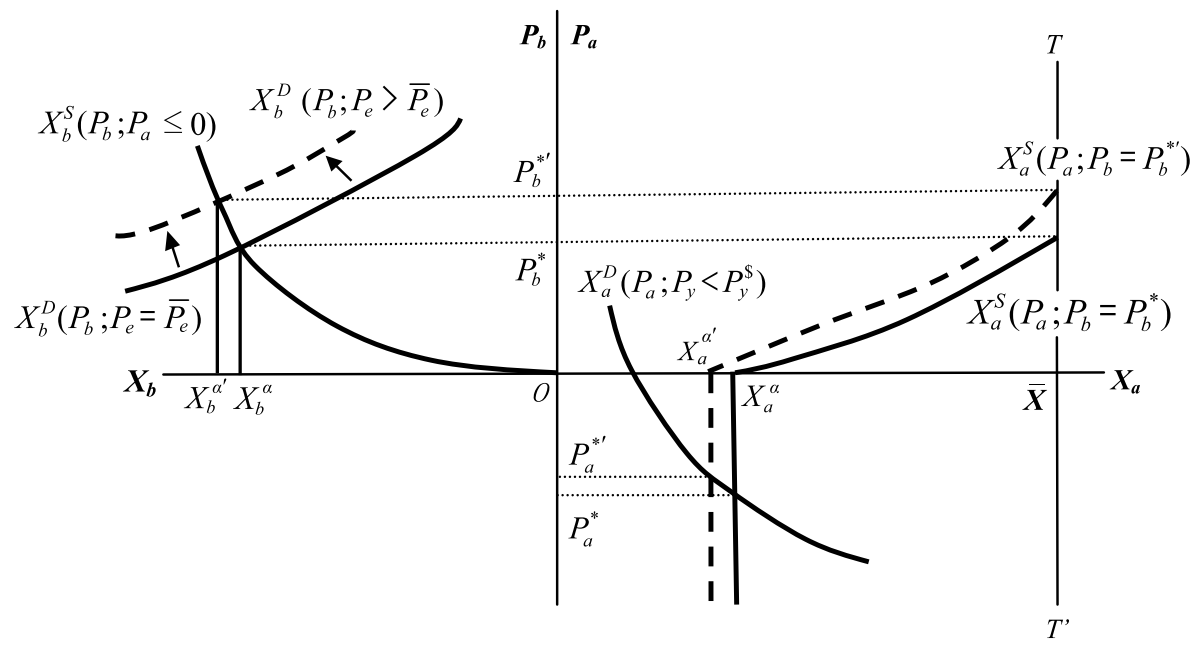

Figure 7 Market Equilibrium with $P_{a} \leq 0$ 
The difference between these two cases is the position of the demand curve of the designated recyclers, which is affected by the domestic price of recycled products $P_{y} . P_{a}$ may be negative when $P_{y}$ is sufficiently low. Another possibility of $P_{a} \leq 0$ is when the export price is sufficiently low.

\subsection{Export price, domestic price, and recycled volume}

This subsection considers the impact of changes in $P_{e}$ and $P_{y}$ on $P_{a}, P_{b}$, and the collected volumes. In the case of positive payments $\left(P_{a}>0\right)$, an increase in the export price $P_{e}$ shifts the demand curve for the non-designated recyclers $X_{b}^{D}$ upward, which raises $P_{b}$ along the supply curve $X_{b}^{S}$. An increase in $P_{b}$ therefore affects both $X_{a}^{S}$ and $X_{b}^{S}$. An increase in $P_{b}$ increases the municipality's marginal revenue from non-designated recyclers (shifting $X_{b}^{S}$ upward), but reduces the supply to the designated recyclers (shifting $X_{a}^{S}$ upward in quadrant I) because $X$ is held constant. A new equilibrium is reached at $P_{a}^{*^{\prime}}$ and $P_{b}^{*^{\prime}}$, where demand is equal to supply along the two recycling routes and $X_{a}^{*^{\prime}}+X_{b}^{*^{\prime}}=\bar{X}$ is satisfied.

In summary, an increase in the export price raises the domestic price of recyclable materials for both designated and non-designated recyclers, but leads to an increase in the volume delivered to non-designated recyclers and a decrease in the volume delivered to designated recyclers, thus producing what is known as the crowding-out effect of exports on domestic recycling. ${ }^{10)}$

An increase in the domestic price of recycled products $P_{y}$ also leads to an increase in $P_{a}$ and $P_{b}$ as it shifts $X_{a}^{D}$ to the right. However, the effect of the increase in the volume of recyclable materials is the opposite of what occurs with a change in the export price; that is, an increase in $P_{y}$ leads to an increase in the volume of recyclable materials along the designated recycling route, whereas a decrease in the volume along the non-designated recycling route. When $P_{a} \leq 0$, a change in export price affects the price for non-designated recyclers $P_{b}$, which affects $X_{a}^{S}$ and thus changes $P_{a}$, as shown by the shift in $X_{b}^{D}$ in Figure 7. Thus, a change in the domestic price affects $P_{a}$ but not the volume of recyclable materials. ${ }^{11)}$

This analysis is consistent with the actual movements of the prices of used PET bottles shown in Figure 3. The fact that $P_{a}$ remained negative for 9 years and showed a gradual increase can be explained by the lower prices of $P_{y}$ and $P_{e}$ and the gradual rise in $P_{y}$, respectively. The parallel movements of $P_{a}$ with $P_{y}$ and $P_{b}$ with $P_{e}$ in Figure 3 are also explained by the model, which depicts the manner in which $P_{a}$ and $P_{b}$ are directly affected by $P_{y}$ and $P_{e}$, respectively.

10) Technically, crowding-out does not occur within the domestic industry producing recycled products, as non-designated recyclers, who are realizing increases in volume, are also members of that industry. However, a decrease in the quantity transferred along the designated recycling route leads to a decline in the domestic manufacture of final products due to the shortage of recyclable materials.

11) Domestic prices are also affected by the total volume of recyclables $\bar{X}$. An increase in $\bar{X}$ shifts $T T^{\prime}$ to the right, decreases $P_{a}$ and $P_{b}$, and increases $X_{b}$. 


\section{Welfare Effects of the "Smooth Delivery of Waste Plastic Bottles"}

This section analyzes the welfare effects of ensuring the "smooth delivery of waste plastic bottles" to designated recyclers, one of the policy changes adopted in the Containers and Packaging Recycling Law. The primary purpose of the "smooth delivery of waste plastic bottles" clause was to remediate the shortage of used PET bottles transferred to designated recyclers. To analyze the impact of this clause, two benchmark cases, one without nondesignated recyclers and one with non-designated recyclers are considered here.

The first case assumes that recycling through the non-designated recyclers is prohibited, so that the entire volume of sorted collection of used PET bottles is processed by designated recyclers. As municipalities would transfer all these bottles to designated recyclers, the supply curve for designated recyclers is given by $T T^{\prime}$ in Figure 6 . On the other hand, the demand curve crosses the horizontal axis, owing to the assumption that the price of recycled products is less than the marginal cost at $\bar{Y}_{a}$, as shown in Figure 5. The supply curve $T T^{\prime}$ and the demand curve $X_{a}^{D}$ intersect at the negative price.

In the second case, which allows the participation of non-designated recyclers in the market for recyclable materials, the price of used PET bottles is positive if the export price is sufficiently high and negative if the domestic price of recycled products is sufficiently low, as shown in Figure 6. Regarding a comparison of the level of welfare at the same domestic price of recycled goods in both cases, the domestic price $P_{y}$ is assumed to be $P_{y}^{\$}$. The level of welfare is assumed to be measured by the sum of the net revenues of municipalities, the profits of recyclers, and the commission payments charged to the specified businesses. The export of recycled goods is assumed to have no negative environmental impact on the importing country. Based on these assumptions, the level of welfare in the first case is given as follows.

Case 1: Without Non-Designated Recyclers

- Municipalities' net revenue $=-C_{g}(\bar{X})$

- Designated recyclers' profits $=P_{y}^{\$} \bar{Y}_{a}-P_{a}^{*} \bar{X}-C_{a}\left(\bar{Y}_{a}\right)$

- Commission Payments by the specified businesses $=P_{a}^{*} \bar{X}$

The level of welfare is given by the following equation.

$$
P_{y}^{\$} \bar{Y}_{a}-C_{a}\left(\bar{Y}_{a}\right)-C_{g}(\bar{X})
$$

Note that the sign of the term $P_{y}^{\$} \bar{Y}_{a}-C_{a}\left(\bar{Y}_{a}\right)$ can be either positive or negative.

The level of welfare in the second case, in which the price for the designated recyclers $P_{a}^{*}$ is positive and the production level of recycled goods $Y_{a}^{*}$ at $P_{a}^{*}$ is smaller than $Y_{a}^{\$}$, as is shown in Figure 5, is given as follows.

Case 2: With Non-designated Recyclers

- Municipalities' net revenue $=P_{a}^{*} X_{a}^{*}+\alpha\left(X_{b}^{*}\right) P_{b}^{*} X_{b}^{*}-C_{g}(\bar{X})$

- Designated recyclers' profits $=P_{y}^{\$} Y_{a}^{*}-P_{a}^{*} X_{a}^{*}-C_{a}\left(Y_{a}^{*}\right)$ 
- Non-designated recyclers' profits $=\bar{P}_{e} Y_{b}^{*}-P_{b}^{*} X_{b}^{*}-C_{b}\left(Y_{b}^{*}\right)$

By summing these up, we obtain

$$
\left[\left(\alpha\left(X_{b}^{*}\right)-1\right) P_{b}^{*} X_{b}^{*}\right]+\left[P_{y}^{*} Y_{a}^{*}-C_{a}\left(Y_{a}^{*}\right)\right]+\left[\bar{P}_{e} Y_{b}^{*}-C_{b}\left(Y_{b}^{*}\right)\right]-C_{g}(\bar{X})
$$

The first term in equation (13) represents the expected loss caused by unexpected fluctuations in the international market, while the second and third terms indicate the benefits from sales of recycled products in the domestic and export market, respectively. By subtracting equation (13) from equation (12), we obtain equation (14) as given below.

$$
-\left(\alpha\left(X_{b}^{*}\right)-1\right) P_{b}^{*} X_{b}^{*}+D
$$

where $D=P_{y}^{\$}\left(\bar{Y}_{a}-Y_{a}^{*}\right)+C_{a}\left(Y_{a}^{*}\right)-C_{a}\left(\bar{Y}_{a}\right)-\left(\bar{P}_{e} Y_{b}^{*}-C_{b}\left(Y_{b}^{*}\right)\right.$. The sign of $D$ is likely to be negative, ${ }^{12)}$ while the sign of the first term in equation (14) is positive and increasing in $X_{b}^{*}$. Therefore, when $X_{b}^{*}$ is small, the sign of equation (14) is negative, and the level of welfare with the participation of non-designated recyclers is higher than that without them. However, if $X_{b}^{*}$ is sufficiently large, the sign of equation (14) becomes positive, which indicates that the level of welfare without non-designated recyclers is higher than that with them.

When the price for the designated recyclers is negative as a result of a significant decrease in the domestic price of recycled goods in case 2 , the results are the same as the above.

\section{Concluding Remarks}

This study conducted a positive and a normative analysis of the Japanese recycling system for used PET bottles. In terms of a positive analysis, a simple model of the recycling system was presented that incorporated uncertainty in the export market and provided a theoretical explanation of not only the observations regarding the movement of prices but also the crowding-out effect of exports on domestic recycling. In terms of a normative analysis, the level of welfare achieved under a government policy mandating a closed system (i.e., permitting only a designated recycling route) was compared to that achieved under a policy allowing an open system via international trade (i.e., allowing a non-designated recycling route). The level of welfare achieved depends on two contrasting factors: the gains realized from trade versus the uncertainty faced in the international market. Therefore, greater stability in the international market for recycled materials leads to a higher level of welfare under an open system than that under a closed system.

Despite this fact, some have argued in favor of a closed system. First, Hosoda (2008, p.350) points out that 10 to $20 \%$ of the total volume of compressed used PET bottles is refuse and they are unlikely to be treated properly in overseas recycling plants. Thus, if non-designated recyclers export improperly processed PET bottles, they export

12) The tern $P_{y}^{\$}\left(\bar{Y}_{a}-Y_{a}^{*}\right)+C_{a}\left(Y_{a}^{*}\right)-C_{a}\left(\bar{Y}_{a}\right)$ in $D$ is equivalent to $\beta-\gamma$ in Figure 5 , where $Y_{a}^{0}$ is regarded as $Y_{a}^{*}$. Even if $\beta>\gamma, \bar{P}_{e} Y_{b}^{*}-C_{b}\left(X_{b}^{*}\right)>0$ holds, hence, $D$ is likely to be negative. 
environmental damage as well, and monitoring their processing to prevent the export of environmental damage is likely to be difficult. Theoretically, a welfare analysis must consider the environmental damage imposed on trading partners. In practice, China maintains a compulsory registration system to ensure that the import of waste materials conforms to environmental standards and other regulations. ${ }^{13)}$ Exporters of waste materials, including used PET bottles, are required to register with the Chinese authorities prior to shipping so that improperly treated waste materials can be detected at the border. By adopting such methods, permitting free trade while requiring rigorous inspection at the border may allow markets to realize gains from trade while reducing the risk of pollution dumping.

Second, Niimiya (2007) argued that the designated recycling process contributes to "developing recycling technology, but furthermore, investing in new technology for using the recyclable materials and new products." This argument implies that the export of recyclable materials may hinder the development of the recycling technology and industry owing to the leakage of secondary materials through the non-designated route, and may even lead to the collapse of the domestic recycling system.

This argument reminds us of the infant industry argument which is applied to the recycling industry. However, the required technology or industry must be sufficiently technology-intensive to be internationally competitive in the future Japan. An example of such a technology employing used PET bottles is a form of chemical recycling that converts old polyester products into new raw materials of the same purity as those manufactured from petroleum. One application of chemical recycling is "bottle-to-bottle recycling," which was launched in 2003 by Tei-jin Ltd Co. However, the company decided to suspend its operations in 2005 and end them completely in 2008 because of a shortage of used PET bottles and higher bidding prices for them. The question now is whether a protective trade policy should be adopted to protect and nurture such an industry. The standard economic answer is certainly "no," even if government intervention was proven to be necessary. A direct policy of subsidization to support the development of such technology is preferable to the imposition of trade restrictions.

Except such high technology, the dominant recycling process of used PET bottles is "material recycle," as analyzed in this study. A certain number of final manufacturing products made from plastic flakes or pellets, which include such diverse products as padding for stuffed dolls, clothes, buckets, and egg cartons, face competition with products produced overseas. As the manufacturing process of such products tends to be low-technology-intensive and high labor-intensive relative to chemical recycling, it may be difficult for Japan to realize a comparative advantage from this type of recycling industry in a globalized world.

Finally, it must be noted that the domestic price of recyclable materials along both the designated and nondesignated routes does not reflect collection expenses, which are borne by local governments. This indicates that the prevailing prices are lower than the true prices inclusive of collection costs, and this may be one reason for the increased flow of recyclable plastic from Japan to the developing countries. Rather than protecting the domestic

13) See the homepage of the private company entrusted by the Chinese government to inspect recyclable materials and used machines prior to shipping: http://www.ccicjapan.com/ 
recycling industry by enacting a deliberative policy under the present system, it may be preferable to improve the present system so that the price of recyclable materials reflects their social costs.

\section{References}

[ 1 ] Bigsten, Arne and Rick Wicks (1996), "Used-Clothes Exports to the Third World: Economic Consideration," Development Policy Review, 14, 379-390.

[ 2 ] Council of PET Bottle Recycling (2008), Annual Report, http://www.petbottle-rec.gr.jp/nenji/2008.

[ 3 ] Duraiappah, Anantha Kumer, Zhou Xin, and Pieter J.H. van Beukering (2002), "Issues in Production, Recycling and International Trade: Analysing the Chinese Plastic Sector Using an Optimal Life Cycle (OLC) Model," Environment and Development Economics, 7, 47-74.

[ 4 ] Grace, Richard, R. Kerry Turner and Ingo Walter (1978), "Secondary Materials and International Trade," Journal of Environmental Economics and Management 5, 172-186.

[ 5 ] Haggblade, Steven (1990), "The Flip Side of Fashion: Used Clothing Exports to the Third World," Journal of Development Studies, 26(3), 505-521.

[ 6 ] Hosoda, Eiji (2008), Design of a Material Circulating Society (Shigen junkangata shakai, in Japanese), Keio University Press.

[ 7 ] Kojima, Michikazu (ed.) (2005), Trade of Recyclable Materials in Asia, (Ajia ni okeru junkanshigen boueki, in Japanese), Institute of Developing Economies.

[ 8 ] Kurita, Ikuma (2009), Economic Analysis of Recycling Market-A Case of Containers and Packaging (Risaikuru shijo no keizai bunseki-youki housou wo Jirei to shite-, in Japanese) Dissertation to Kyoto university.

[ 9 ] Ministry of the Environment (2006), 'Cabinet Decision on a Bill Partially Amending the Law for the Promotion of Sorted Collection and Recycling of Containers and Packaging,' http://www.env.go.jp/en/press/2006/0309a.html.

[10] Niimiya, Akira (2007), "Stop Overseas Outflow of PET Bottles-New Regulation on the Revised Containers and Packaging Recycling Law,” (PET botoru no kaigai ryuushutsu wo fusege ? Kaisei yourihou ni shinkitei, in Japanese), Nikkei Economy, http://www.jcpra.or.jp/association/ecolomy/2007018.html.

[11] Terazono, Atsushi, Aya Yoshida, Rie Murakami-Suzuki, Shinsuke Murakami, and Takayoshi Shinkuma (2009), Analysis of Material Cycle Systems for E-Waste and Plastics in Asia (Ajia chi-iki ni okeru hai denkidenshikiki to hai purasuchikku no shigen junkan shisutemu no kaiseki, in Japanese), Final Report of the Grants-in-Aid for Scientific Research.

[12] Van Beukering, Pieter J.H. (2001), Recycling, International Trade and the Environment: An Empirical Analysis, Kluwer Academic Publishers, Dordrecht. 